\title{
Determinants of Postoperative Spinal Height Change among Adult Spinal Deformity Patients with Long Construct Circumferential Fusion
}

\author{
Colleen Rentenberger ${ }^{1}$, Ichiro Okano ${ }^{1}$, Stephan N. Salzmann ${ }^{1}$, \\ Toshiyuki Shirahata ${ }^{2}$, Marie-Jacqueline Reisener ${ }^{1}$, Jennifer Shue ${ }^{1}$, \\ Andrew A. Sama ${ }^{1}$, Frank P. Cammisa ${ }^{1}$, Federico P. Girardi ${ }^{1}$, Alexander P. Hughes ${ }^{1}$ \\ ${ }^{1}$ Department of Orthopedic Surgery, Spine and Scoliosis Service, Hospital for Special Surgery, Weill Cornell Medical College, New York, NY, USA \\ ${ }^{2}$ Department of Orthopaedic Surgery, Showa University School of Medicine, Tokyo, Japan
}

Study Design: Retrospective clinical study.

Purpose: To describe postoperative height changes and identify the predictive factors of spinal height (SH) changes among patients with adult spinal deformity (ASD) who underwent circumferential lumbar fusion with instrumentation.

Overview of Literature: Postoperative height changes remain an important issue after spinal fusion surgery that affects the overall satisfaction with surgery. Previous studies of postoperative height change have focused exclusively on young patients with adolescent idiopathic scoliosis (AIS).

Methods: We retrospectively reviewed the clinical and imaging data of ASD patients who underwent lumbar corrective circumferential fusion of $\geq 3$ levels ( $n=106$ ). SH was defined as the vertical distance between C2 and S1 on a standing lateral image. As potential predictors of postoperative height change, the number of lateral lumbar interbody fusion (LLIF) levels, change in spino-pelvic parameters, total number of levels fused, and pedicle subtraction osteotomies (PSO) were documented. Univariate and multivariate linear regression analyses were performed to identify the predictors of postoperative height change.

Results: The mean SH change was $-2.39 \pm 50.8 \mathrm{~mm}$ (range, -160 to $172 \mathrm{~mm}$ ). The univariate analyses showed that the number of LLIF levels (coefficient $=10.9, p=0.03$ ), the absolute coronal vertical axis change (coefficient $=0.6, p=0.01$ ), and the absolute Cobb angle change (coefficient $=-0.9, p=0.03$ ) were significant predictors for height change. Patients with PSOs $(n=14)$ tended to have a shorter height postoperatively (coefficient=-26.1); however, this difference was not significant ( $p=0.07$ ). Multivariate analyses conducted with variables of $p<0.20$ showed that pelvic tilt (PT) change is an independent contributor to SH change (coefficient $=-0.99, p=0.04$, $R^{2}=0.11$.

Conclusions: Utilizing a modified definition of SH used in previous AIS studies, we demonstrated that patients with ASD lose SH postoperatively and that PT change was an independent contributor of SH change.

Keywords: Spinal height; Adult spinal deformity; Lateral lumbar interbody fusion; Circumferential fusion; Thoraco-lumbar spine

Received Jan 10, 2020; Revised Mar 18, 2020; Accepted Apr 1, 2020

Corresponding author: Alexander P. Hughes

Spine Care Institute, Hospital for Special Surgery, 535 East 70th St., New York, NY 10021, USA

Tel: +1-212-774-2992, Fax: +1-646-797-8664, E-mail: tahs.s2003@gmail.com 


\section{Introduction}

Adult spinal deformity (ASD) is a common condition in the elderly population. Schwab et al. [1] reported a prevalence of spinal deformity of $68 \%$ in the elderly population in the United States of America. If symptomatic, this condition can be treated with corrective spinal surgeries that may cause postoperative height changes. Generally with increasing age, people experience a decrease in height even without surgery $[2,3]$. The average height loss from age 30 to 70 years was reported to be $3 \mathrm{~cm}$ for men and 5 $\mathrm{cm}$ for women. Height loss then becomes progressively more rapid, reaching $5 \mathrm{~cm}$ for men and $8 \mathrm{~cm}$ for women by the age of 80 years [3]. Consequently, height changes might be even more pronounced in elderly patients with adult spinal deformities. Deformity corrections and restoration of the spinal balance are important contributors to improved pain and functional outcomes. In addition, height changes remain an important issue that bother patients even in the advanced age and might affect the postoperative overall satisfaction.

Previous studies of postoperative height change have focused exclusively on young patients with adolescent idiopathic scoliosis (AIS) [4-10]. There are several inherent differences between ASD and AIS in terms of height change. For AIS patients, the primary treatment corrects the coronal deformity within the thoracolumbar region and sagittal spinal parameters are often less relevant [11]. However, in ASD cases, sagittal balance as well as pelvic and cervical factors should be considered more carefully. For instance, Banno et al. [12] showed gradual pelvic tilt (PT), and pelvic incidence-lumbar lordosis mismatch (PILL) increases with age, while sagittal vertical axis (SVA) increases were significant after the 7 th decade. Furthermore, the deterioration in the quality of life was related to sagittal malalignment [13-15]. Currently, it is unclear whether AIS results can be applied to ASD cases.

Moreover, lateral lumbar interbody fusion (LLIF) and pedicle subtraction osteotomy (PSO) are common procedures for ASD, especially for severe deformity cases $[16,17]$. These procedures could cause significant changes in the postoperative height. Regarding the LLIF procedure, interbody fusion is often associated with local disc height gain that may lead to overall spinal height (SH) increase. The effect of PSO on $\mathrm{SH}$ is more complex. PSO usually results in the loss of local segmental length because of the bone-removing aspect of the procedure.
PSOs can also improve the sagittal balance parameters considerably and can have varying effects on the overall $\mathrm{SH}$. Therefore, these PSO factors should be assessed along with the spinal balance parameters for patients with ASD.

In this study, we analyzed the clinical and imaging data of ASD patients who underwent combined anterior and posterior fusion to describe postoperative height changes and to identify the potential contributors to height change.

\section{Materials and Methods}

\section{Study population}

This study was approved by the Institutional Review Board at the Hospital for Special Surgery (IRB approval no., 2014-097). A waiver for the documentation of informed consent was provided by the IRB according to 45 CFR 46.117(c). Data were retrieved from a retrospectively collected database at Hospital for Special Surgery from 2007 to 2018. ASD patients who were undergoing spinal surgery for common indications, including spinal stenosis, foraminal stenosis, degenerative disc disease, spondylolisthesis, neurogenic claudication, herniated nucleus pulposus, adjacent segment disease, and pseudarthrosis were examined.

All surgeries were performed by five fellowship-trained spinal surgeons. The study inclusion criteria were as follows: (1) circumferential approach with at least one level treated with LLIF and a posterior pedicle screw construct of at least four levels, (2) available preoperative computed tomography (CT) scans and 91.44-cm long-cassette radiographs, and (3) available postoperative long-cassette radiographs within 8 weeks after the surgery. Total 104 patients met the inclusion criteria and were included in the analyses.

\section{Assessment of height change}

Radiographic assessment of height change was performed using pre- and postoperative long-cassette radiographs. After calibrating the images utilizing the anteroposteriorand lateral width of the S1 endplate on preoperative CT scans, all the radiological parameters were measured and calculated using the Sectra IDS7 picture archiving and communication system (Sectra Corp., Linkping, Sweden).

In this study, $\mathrm{SH}$ was defined as the vertical distance 


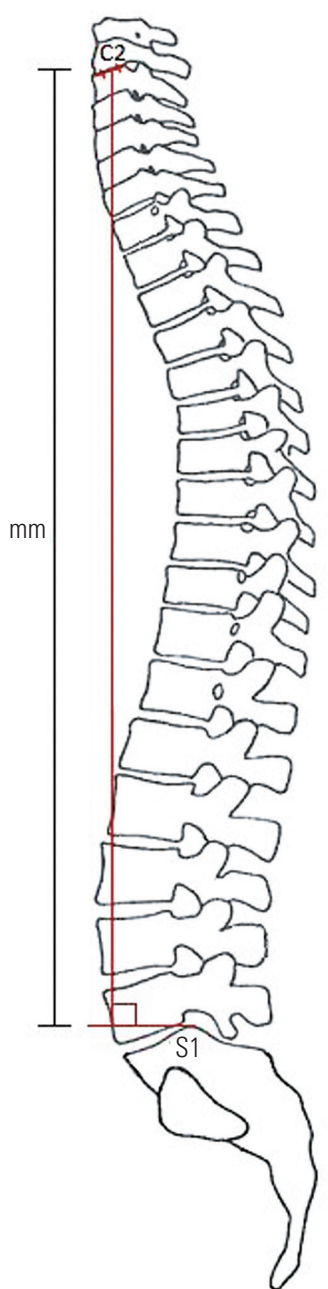

Fig. 1. Schematic representation of spinal height measurement (mm).

between the midpoint of the $\mathrm{C} 2$ endplate and the posterosuperior aspect of the S1 endplate on a standing lateral image (Fig. 1). Additional spinopelvic parameters that were measured included the following: coronal vertical axis (CVA; horizontal distance between the plumb line from $\mathrm{C} 7$ and the midpoint of the sacral endplate), coronal Cobb angle, SVA (horizontal distance between the C7 centroid and the posterosuperior aspect of the sacral endplate), PT (angle between a vertical line and a connecting line between the middle of the sacral endplate and the middle of the bicoxofemoral axis), lumbar lordosis (LL; angle between the superior endplate of L1 and the superior endplate of S1), PI-LL, and thoracic kyphosis (TK; angle between the superior endplate of $\mathrm{T} 4$ and the inferior endplate of T12). The radiologic assessment was conducted by two independent examiners who did not directly participate in the care of patients in the study cohort. The

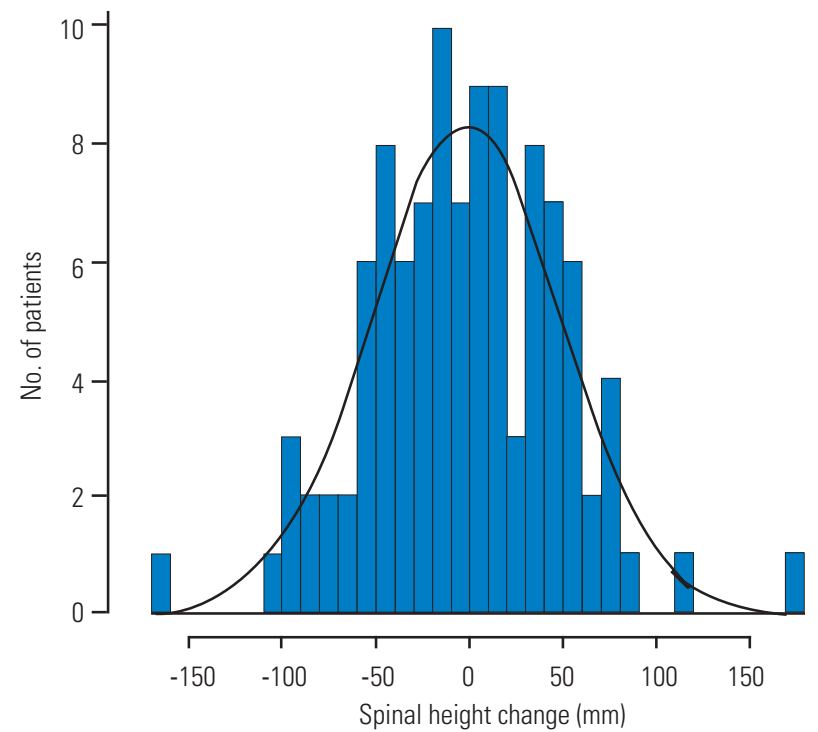

Fig. 2. Spinal height change $(\mathrm{mm})$ showing an approximate normally distributed bell-shaped curve.

number of LLIF levels, the total number of levels fused, and PSO were also documented.

Univariate and multivariate linear regression analyses were used to determine the significance of contributors for postoperative height change. Variables with a $p$-value of $<0.20$ in the univariate analyses were included in the multivariate analysis. The statistical significance level was set at $p<0.05$. All the statistical analyses were performed using EZR ver. 1.3.7 (Saitama Medical Center, Jichi Medical University, Saitama, Japan) [18] a statistical software based on the $\mathrm{R}$ environment ( $\mathrm{R}$ for 3.1.0 [The R Foundation for Statistical Computing, Vienna, Austria]; graphical user interface, 1.64).

\section{Results}

\section{Patient demographics and postoperative parameter change}

Total 77 of the 104 patients were women (74.0\%). The mean \pm standard deviation patient age at surgery was $64.7 \pm 9.2$ years (range, $33-82$ years), the mean body mass index was $28.6 \pm 6.4 \mathrm{~kg} / \mathrm{m}^{2}$ (range, $17.2-55.4 \mathrm{~kg} / \mathrm{m}^{2}$ ). The mean number of levels fused was $7.0 \pm 2.6$ (range, 4-22) that included the previous fusion levels. The mean number of LLIF levels was 2.6 \pm 1.0 (range, 1-4). Fourteen patients underwent additional PSO. The mean SH change was $-2.63 \pm 51.2 \mathrm{~mm}$ (range, -160 to $172 \mathrm{~mm}$ ) (Fig. 2). 
Table 1. Description of the study population including summary of preoperative parameters

\begin{tabular}{lc}
$\begin{array}{l}\text { Characteristic } \\
\text { Age (yr) }\end{array}$ & \multicolumn{1}{c}{ Value } \\
$\begin{array}{l}\text { Sex } \\
\text { Female }\end{array}$ & 77 \\
\hline Male & 27 \\
\hline Body mass index $\left(\mathrm{kg} / \mathrm{m}^{2}\right)$ & $28.6 \pm 6.4(17.2$ to 55.4$)$ \\
\hline Preoperative parameters & \\
\hline Spinal height $(\mathrm{mm})$ & $479.3 \pm 61.7(312.0$ to 647.0$)$ \\
\hline Sagittal vertical axis $(\mathrm{mm})$ & $70.1 \pm 60.5(-31.0$ to 392.0$)$ \\
\hline Coronal vertical axis $(\mathrm{mm})$ & $21.7 \pm 18.6(0.0$ to 93.0$)$ \\
\hline Coronal Cobb angle $\left(^{\circ}\right)$ & $28.3 \pm 16.0(2.0$ to 98.0$)$ \\
\hline LL $\left(^{\circ}\right)$ & $36.8 \pm 19.2(-7.0$ to 80.0$)$ \\
\hline Pelvic tilt $\left({ }^{\circ}\right)$ & $29.4 \pm 10.7(5.0$ to 70.0$)$ \\
\hline PI-LL $\left(^{\circ}\right)$ & $23.1 \pm 19.7(-29.0$ to 78.0$)$ \\
\hline Thoracic kyphosis $\left({ }^{\circ}\right)$ & $34.9 \pm 16.1(-2.0$ to 76.0$)$ \\
\hline
\end{tabular}

Values are presented as mean \pm standard deviation (range) or number. LL, lumbar lordosis; PI-LL, pelvic incidence-lumbar lordosis mismatch.

Demographic and preoperative data are detailed in Table 1 , and the pre- to postoperative parameter changes are shown in Table 2.

\section{Univariate analyses}

Univariate analyses showed that female sex (coefficient $=23.0, p=0.5$ ), number of LLIF levels (coefficient $=11.07, p=0.03$ ), absolute amount of CVA change (coefficient $=0.6, p=0.01$ ), and the absolute amount of Cobb angle change (coefficient $=-0.9, p=0.03$ ) were significant predictors for height gain. Patients with PSO $(n=14)$ had a shorter height postoperatively (coefficient $=-25.8$ ); however, this finding was not statistically significant $(p=0.08)$ (Table 3).

\section{Multivariate analysis}

Multivariate analyses conducted on variables with $p<0.20$ (sex, absolute amounts of CVA and Cobb change, PT change, LLIF levels, and PSO) showed that PT change was an independent negative contributor to $\mathrm{SH}$ change (coefficient $=-0.99, p=0.04, R^{2}=0.12$ ). CVA change, patients who underwent PSO, and female sex trended toward significance, but were not statistically significant factors $(p=0.06$, $p=0.10$, and $p=0.05$, respectively) (Table 4 ).
Table 2. Description of postoperative parameters and pre- to postoperative changes

\begin{tabular}{|c|c|}
\hline Characteristic & Value \\
\hline \multicolumn{2}{|c|}{ Postoperative parameters } \\
\hline Spinal height (mm) & $476.7 \pm 61.7$ (332.0 to 646.0$)$ \\
\hline SVA (mm) & $52.4 \pm 46.4(-70.0$ to 164.0$)$ \\
\hline CVA (mm) & $20.4 \pm 16.4(0.0$ to 78.0$)$ \\
\hline $\operatorname{Cobb}\left({ }^{\circ}\right)$ & $11.7 \pm 8.1$ (0.0 to 41.0$)$ \\
\hline $\operatorname{LL}\left({ }^{\circ}\right)$ & $48.5 \pm 11.9(16.0$ to 73.0$)$ \\
\hline $\operatorname{PT}\left({ }^{\circ}\right)$ & $25.2 \pm 10.4(1.0$ to 53.0$)$ \\
\hline PI-LL $\left(^{\circ}\right)$ & $11.4 \pm 14.8(-17.0$ to 58.0$)$ \\
\hline TK $\left({ }^{\circ}\right)$ & $42.4 \pm 13.3$ (8.0 to 78.0 ) \\
\hline LIFF levels & $2.6 \pm 1.0(1.0$ to 4.0$)$ \\
\hline No. of 1 level & $19 \pm 18.3$ \\
\hline No. of 2 levels & $31 \pm 27.9$ \\
\hline No. of 3 levels & $35 \pm 33.7$ \\
\hline No. of 4 levels & $21 \pm 20.2$ \\
\hline \multicolumn{2}{|l|}{ PSO (+/-) } \\
\hline No. of PSO & 14 \\
\hline No. of no PSO & 90 \\
\hline No. of total fusions & $7.0 \pm 2.6$ (4.0 to 22.0$)$ \\
\hline \multicolumn{2}{|c|}{ Pre- to postoperative changes } \\
\hline Spinal height (mm) & $-2.6 \pm 51.2$ (-160.0 to 172.0$)$ \\
\hline SVA (mm) & $-17.6 \pm 59.2(-229.0$ to 101.0$)$ \\
\hline $\mathrm{CVA}^{\mathrm{al}}(\mathrm{mm})$ & $21.2 \pm 21.5(0.0$ to 110.0$)$ \\
\hline $\operatorname{Cobb}^{\text {a) }}\left({ }^{\circ}\right)$ & $16.8 \pm 22.7(0.0$ to 64.0$)$ \\
\hline $\operatorname{LL}\left({ }^{\circ}\right)$ & $11.7 \pm 15.4$ (-20.0 to 54.0$)$ \\
\hline $\operatorname{PT}\left({ }^{\circ}\right)$ & $-4.2 \pm 11.0(-46.0$ to 26.0$)$ \\
\hline $\operatorname{PI}-L L\left(^{\circ}\right)$ & $-11.7 \pm 15.4(-54.0$ to 20.0$)$ \\
\hline $\operatorname{TK}\left(1^{\circ}\right)$ & $7.6 \pm 11.0$ (-15.0 to 35.0$)$ \\
\hline
\end{tabular}

Values are presented as mean \pm standard deviation (range) or number SVA, sagittal vertical axis; CVA, coronal vertical axis; Cobb, coronal Cobb angle; $\mathrm{LL}$, lumbar lordosis; PT, pelvic tilt; PI-LL, pelvic incidence-lumbar lordosis mismatch; TK, thoracic kyphosis; LLIF, lateral lumbar interbody; PSO, pedicle subtraction osteotomy.

${ }^{a)} \mathrm{CVA}$ and Cobb changes are absolute amounts of change. For example, if a patient tilted $5 \mathrm{~mm}$ on the left preoperatively, then tilted $3 \mathrm{~mm}$ on the right postoperatively, the CVA change is $8 \mathrm{~mm}$.

\section{Sub-analyses}

The study population was subdivided into a pure sagittal deformity group, including patients with a preoperative Cobb angle $\leq 30^{\circ}(\mathrm{n}=57)$. The univariate analyses showed that the LL change was significantly $(p=0.04)$ correlated to height loss. This was not true for patients with sagittal and coronal deformities $(p=0.62)$. However, there was a sig- 
Table 3. Univariate analysis

\begin{tabular}{|c|c|c|c|}
\hline Characteristic & Coefficient & $p$-value & $\begin{array}{c}95 \% \\
\text { Confidence } \\
\text { interval }\end{array}$ \\
\hline Age & 0.33 & 0.55 & 1.42 to -0.77 \\
\hline Body mass index & -0.48 & 0.55 & 1.10 to -2.07 \\
\hline Sex & 22.95 & 0.05 & 45.33 to 0.58 \\
\hline \multicolumn{4}{|l|}{ Pre- to postoperative changes } \\
\hline Sagittal vertical axis & 0.06 & 0.45 & 0.23 to -0.11 \\
\hline$C V A^{a)}$ & 0.58 & 0.01 & 1.04 to 0.13 \\
\hline $\mathrm{Cobb}^{\mathrm{a})}$ & 0.94 & 0.03 & 1.78 to 0.10 \\
\hline Lumbar lordosis & -0.26 & 0.43 & 0.39 to -0.92 \\
\hline Pelvic tilt & -0.70 & 0.13 & 0.22 to -1.61 \\
\hline Thoracic kyphosis & -0.55 & 0.24 & 0.37 to -1.46 \\
\hline Lateral lumbar interbody level & 11.07 & 0.03 & 20.76 to 1.38 \\
\hline Pedicle subtraction osteotomy & -25.84 & 0.08 & 3.03 to -54.72 \\
\hline No. of levels fused & -0.81 & 0.73 & 3.92 to -5.54 \\
\hline
\end{tabular}

Boldface indicates statistical significance.

CVA, coronal vertical axis; Cobb, coronal Cobb angle.

${ }^{a} \mathrm{CVA}$ and Cobb changes are absolute amounts of change. For example, if a patient tilted $5 \mathrm{~mm}$ on the left preoperatively, then tilted $3 \mathrm{~mm}$ on the right postoperatively, the CVA change is $8 \mathrm{~mm}$.

Table 4. Multivariate analysis including variables with $p<0.20$

\begin{tabular}{lccc} 
Variable & Coefficient & $p$-value & $\begin{array}{c}95 \% \\
\text { Confidence } \\
\text { interval }\end{array}$ \\
\hline $\begin{array}{l}\text { Pre- to postoperative changes } \\
\quad\end{array}$ & 0.45 & 0.06 & 0.93 to -0.02 \\
\hline CVA $^{\text {a) }}$ & -0.01 & 0.99 & 0.96 to -0.98 \\
\hline Cobb $^{\text {a) }}$ & -0.99 & 0.04 & -0.03 to -1.95 \\
\hline Pelvic tilt & 5.54 & 0.29 & 15.81 to -4.73 \\
\hline Lateral lumbar interbody level & -27.84 & 0.10 & 45.51 to -56.71 \\
\hline Pedicle subtraction osteotomy & 22.73 & 0.05 & 5.02 to -0.5 \\
\hline Sex & 0.12 & & \\
\hline$R^{2}$ & & & \\
\hline
\end{tabular}

Boldface indicates statistical significance.

CVA, coronal vertical axis; Cobb, coronal Cobb angle.

${ }^{a} \mathrm{CVA}$ and Cobb changes are absolute amounts of change. For example, if a patient tilted $5 \mathrm{~mm}$ on the left preoperatively, then tilted $3 \mathrm{~mm}$ on the right postoperatively, the CVA change is $8 \mathrm{~mm}$.

nificant positive correlation for CVA change $(p<0.01)$ and a negative correlation for PT change $(p=0.02)$ with height change for the sagittal and coronal deformity group (Table $5)$.

\section{Discussion}

In this study, we utilized a modified definition of $\mathrm{SH}$ used in previous AIS studies to include characteristics of ASD. The results of our study demonstrated that $>50 \%$ of ASD patients lost SH postoperatively, and the PT change was an independent contributor to this $\mathrm{SH}$ change in the multivariate analysis. The results of univariate analyses showed that LLIF had a significant positive association with postoperative $\mathrm{SH}$, while $\mathrm{PSO}$ demonstrated a negative trend effect on postoperative $\mathrm{SH}$.

To our knowledge, no reports have evaluated the postoperative SH change among ASD patients. In AIS reports, the definition of SH was the distance between C7/T1 and L5 [7-10]. For ASD cases, patients may have a deformity in the upper thoracic and/or cervical spine that might affect the head-to-heel body height. Furthermore, identifying the correct point of the $\mathrm{C} 7$ or $\mathrm{T} 1$ vertebra for measurement can be challenging, especially on the posteroanterior radiographs, owing to age-related degenerative changes in the spine. Thus, we considered the SH definition in AIS studies potentially error-prone for ASD cases $[19,20]$.

Postoperative SH change among AIS patients was distinct from our ASD results because AIS patients were more likely to gain $\mathrm{SH}$ postoperatively in previous studies [4-10]. It has been theorized that associated ASD procedures may cause height loss. Although it was not significant in our cohort $(p=0.08)$, PSOs tended to decrease $\mathrm{SH}$, accounting for an approximate $2.6 \mathrm{~cm}$ of SH loss. In contrast, Hwang et al. [4] showed that body height in AIS patients with osteotomies significantly increased postoperatively and was most likely owing to the increased coronal curve correction in their population. Although surgical procedure information was not detailed in their study, the effect of osteotomies on coronal balance correction and SH should be different from PSOs in the lumbar spine. The negative effect of PSOs on SH might not have been attributed to osteotomy itself, but to the sagittal balance correction issue as mentioned above. Lafage et al. [21] reported a mean LL gain of $29^{\circ}$ after a PSO. Although the Cobb angles were not reported, majority of their study population had sagittal deformities. In our study, $1^{\circ}$ of LL change resulted in a height loss of $0.84 \mathrm{~mm}$. If applied to the population of Lafage et al. [21], the $0.84-\mathrm{mm}$ height loss per degree of LL change would be an equivalent height loss of approximately $24 \mathrm{~mm}$, comparable to the estimated height loss with PSOs in our patients with pure 
Table 5. Sub-group analysis divided in pure sagittal and sagittal with coronal deformity groups

\begin{tabular}{|c|c|c|c|}
\hline Variable & Coefficient & $p$-value & 95\% Confidence interval \\
\hline \multicolumn{4}{|c|}{ Pure sagittal deformities: Cobb $\leq 30^{\circ}(n=57)$} \\
\hline Age & -0.25 & 0.71 & 1.08 to -1.58 \\
\hline $\mathrm{BMl}$ & 0.14 & 0.90 & 2.28 to -2.00 \\
\hline Sex & 6.84 & 0.61 & 33.81 to -20.14 \\
\hline \multicolumn{4}{|c|}{ Pre- to postoperative changes } \\
\hline SVA & 0.15 & 0.25 & 0.42 to -0.11 \\
\hline$C V A^{a)}$ & -0.12 & 0.74 & 0.58 to -0.82 \\
\hline Cobb $^{\text {al }}$ & 0.11 & 0.91 & 2.06 to -1.84 \\
\hline $\mathrm{LL}$ & -0.84 & 0.04 & -0.03 to -1.64 \\
\hline PT & -0.31 & 0.60 & 1.46 to -0.85 \\
\hline TK & -0.82 & 0.18 & 0.39 to -2.02 \\
\hline LLIF level & 6.68 & 0.28 & 18.87 to -5.51 \\
\hline PSO & -18.09 & 0.27 & 14.60 to -50.78 \\
\hline No. of levels fused & -2.43 & 0.34 & 2.68 to -7.53 \\
\hline \multicolumn{4}{|c|}{ With coronal deformities: Cobb $>30^{\circ}(n=47)$} \\
\hline Age & 1.19 & 0.20 & 3.02 to -0.64 \\
\hline $\mathrm{BMI}$ & -0.35 & 0.78 & 2.11 to -2.80 \\
\hline Sex & 41.88 & 0.06 & 86.03 to -2.28 \\
\hline \multicolumn{4}{|c|}{ Pre- to postoperative changes } \\
\hline SVA & 0.004 & 0.97 & 0.23 to -0.22 \\
\hline$C A^{\text {al }}$ & 0.96 & $<0.01$ & 1.54 to 0.38 \\
\hline $\mathrm{Cobb}^{\mathrm{al}}$ & 0.60 & 0.44 & 2.17 to -0.96 \\
\hline $\mathrm{LL}$ & 0.26 & 0.62 & 1.31 to -0.79 \\
\hline PT & -1.76 & 0.02 & -0.33 to -0.32 \\
\hline TK & -0.79 & 0.27 & 0.62 to -2.20 \\
\hline LLIF level & 14.11 & 0.09 & 30.29 to -2.08 \\
\hline PSO & -25.85 & 0.41 & 36.34 to -88.04 \\
\hline No. of levels fused & 4.09 & 0.44 & 14.82 to -6.63 \\
\hline
\end{tabular}

Boldface indicates statistical significance.

BMI, body mass index; SVA, sagittal vertical axis; CVA, coronal vertical axis; Cobb, coronal Cobb angle; LL, lumbar lordosis; PT, pelvic tilt; TK, thoracic kyphosis; LLIF, lateral lumbar interbody; PSO, pedicle subtraction osteotomy.

${ }^{\text {al }} \mathrm{CVA}$ and Cobb changes are absolute amounts of change. For example, if a patient tilted $5 \mathrm{~mm}$ on the left preoperatively, then tilted $3 \mathrm{~mm}$ on the right postoperatively, the CVA change is $8 \mathrm{~mm}$.

sagittal deformities (Table 5).

The effect of sagittal spinal correction has a different effect on postoperative SH change compared to coronal spinal correction. While coronal correction leads more directly to height gain via a straightening effect on the spine; sagittal correction is often an amplification of LL and TK that might influence SH negatively by adding curvature to the spine. Similarly, Spencer et al. [8] showed that in addition to the number of levels fused, the magnitude of a major Cobb angle change was positively correlated with height gain in AIS patients. Obtaining sagittal balance through spinal corrective surgery does not necessarily correlate with SH gain in ASD patients [13,22-24]. For instance, in the pure sagittal deformity group in our subgroup analysis, LL change demonstrated a significantly negative association with $\mathrm{SH}$, suggesting that greater sagittal balance correction in ASD patients leads to height loss. Regarding coronal balance, Imrie et al. [25] suggested that 
complete correction in the coronal plane may occur at the expense of sagittal alignment in AIS patients and lead to height gain. Our subgroup analysis supports this trend that the absolute amount of CVA change has a positive correlation to $\mathrm{SH}$ gain $(p<0.01)$.

AIS studies have formulated models to predict the $\mathrm{SH}$ change [4-10]. Keong et al. [5] and Shi et al. [7] included preoperative parameters in their prediction models and concluded coronal deformity factors (preoperative Cobb angle or postoperative Cobb angle change) were significant contributors to height change. In our study, univariate analyses demonstrated a positive association between the change in the $\mathrm{SH}$ and change in the Cobb angle/CVA. The multivariate analysis only showed a trend toward significance for CVA change $(p=0.06)$. An underpowered sample size might be a reason for not detecting significance in this relatively heterogeneous population. PT change demonstrated statistical significance in the multivariate analyses. High PT reflects a compensatory mechanism for global sagittal malalignment [14]. Therefore if PT is high postoperatively, there might be an under-correction of the sagittal alignment [26,27]. Our results showed that a postoperative PT decrease was associated with $\mathrm{SH}$ increase. PT is associated with other sagittal balance parameters; however, none of them showed significance for SH change in our study. PT change might therefore be more sensitive to SH change than other parameters. This independent positive effect of $\mathrm{PT}$ reduction on $\mathrm{SH}$ change seems contradictory to the effect of PSO that showed a trend toward height loss and is likely to be associated with significant PT reduction. The interrelationship between these parameters may explain the significant association for PT in univariate analysis. PSOs and PT change may have had a counterbalancing effect. However, the effect of PT change was significant after adjustment with PSO.

In sum, we found that PT reduction was an independent factor for $\mathrm{SH}$ gain. Owing to our relatively small sample size and the large number of variables evaluated, statistical significance was not observed for other potential SH modifiers in the multivariate analysis. However, our results suggest that factors related to the corrective surgery might be modifiers for postoperative $\mathrm{SH}$. In theory, LLIF surgery could result in the greatest $\mathrm{SH}$ gain, depending on the number of interbody devices. PSOs, on the other hand, are generally associated with a reduction in the SH. Therefore, patients with a well-corrected PT with a multilevel LLIF procedure without a PSO, are likely to obtain the largest SH gain postoperatively. Larger studies are warranted to identify the independent contributors in the multivariate analysis more comprehensively, including procedure-related factors.

This study has certain limitations owing to its retrospective nature and relatively small sample size. First, ASD contains a wide variety of deformities and may be more heterogeneous than AIS. In fact, the $R^{2}$ value was low (0.12) in this study. Another limitation is the lack of information about global (head-to-heel) height change. However, the postoperative global height could be inaccurate because postoperative pain can affect the patients' posture, impacting their imaged body height. According to AIS studies that measure the SH [7-9] or body height [4-6], the same trend in height gain after corrective surgery was observed. Our SH results may be applicable to global height as well, but additional studies are necessary to confirm this relationship. Other considerations in the elderly population include the compensation mechanisms involving the lower extremities that might play an important role in postoperative sagittal alignment changes. The compensation mechanisms of the hip and knee joints might also affect global height, especially in the long term in the elderly. Finally, it remains unclear if $\mathrm{SH}$ changes are related to further clinical outcomes, such as revision surgery, correction loss, or adjacent segmental disease. Longitudinal studies are warranted to investigate these factors and outcomes.

\section{Conclusions}

In conclusion, this study demonstrated that $>50 \%$ of the patients with ASD can lose SH postoperatively in contrast to AIS patients, and PT change was an independent contributor to postoperative $\mathrm{SH}$ change. Postoperative height loss may be a concern for some patients, especially in the elderly population where changes may be more pronounced. When counseling patients preoperatively, surgeons should consider discussing $\mathrm{SH}$ changes after the surgery that could affect patient satisfaction. To our knowledge, there is no evidence in the literature on how postoperative height loss after lumbar fusion affects the overall satisfaction with surgery and clinical outcomes and could be studied in the future. 


\section{Conflict of Interest}

No potential conflict of interest relevant to this article was reported.

\section{Author Contributions}

CR collected the data and wrote the manuscript, IO analyzed the data and reviewed and edited the manuscript, SNS collected data, reviewed and edited the manuscript, TS collected the data, JS wrote the research plan for IRB approval and was in charge of the clinical research process and the project administration; AAS designed the study and reviewed and edited the manuscript. FPC designed the study and reviewed and edited the manuscript. FPG designed the study and reviewed and edited the manuscript. APH designed the study, reviewed and edited the manuscript and supervised all aspects of the study. All authors have read and approved the final submitted manuscript.

\section{References}

1. Schwab F, Dubey A, Gamez L, et al. Adult scoliosis: prevalence, SF-36, and nutritional parameters in an elderly volunteer population. Spine (Phila Pa 1976) 2005;30:1082-5.

2. Peter RS, Fromm E, Klenk J, Concin H, Nagel G. Change in height, weight, and body mass index: longitudinal data from Austria. Am J Hum Biol 2014;26:690-6.

3. Sorkin JD, Muller DC, Andres R. Longitudinal change in height of men and women: implications for interpretation of the body mass index: the Baltimore Longitudinal Study of Aging. Am J Epidemiol 1999;150:969-77.

4. Hwang SW, Samdani AF, Lonner BS, et al. A multicenter analysis of factors associated with change in height after adolescent idiopathic scoliosis deformity surgery in 447 patients. J Neurosurg Spine 2013;18:298-302.

5. Keong KM, Aziz I, Yin Wei CC. Prediction of height increment using preoperative radiological parameters following selective thoracic fusion with alternatelevel pedicle screw construct in Lenke 1 and 2 adolescent idiopathic scoliosis patients. J Orthop Surg (Hong Kong) 2017;25:2309499016684431.
6. Sarlak AY, Atmaca H, Musaoglu R, Veliev EV. The height gain in scoliotic deformity correction: assessed by new predictive formula. Comput Math Methods Med 2012;2012:167021.

7. Shi B, Mao S, Xu L, et al. Factors favoring regain of the lost vertical spinal height through posterior spinal fusion in adolescent idiopathic scoliosis. Sci Rep 2016;6:29115.

8. Spencer HT, Gold ME, Karlin LI, Hedequist DJ, Hresko MT. Gain in spinal height from surgical correction of idiopathic scoliosis. J Bone Joint Surg Am 2014;96:59-65.

9. Van Popta D, Stephenson J, Verma R. Change in spinal height following correction of adolescent idiopathic scoliosis. Spine J 2016;16:199-203.

10. Watanabe K, Hosogane N, Kawakami N, et al. Increase in spinal longitudinal length by correction surgery for adolescent idiopathic scoliosis. Eur Spine J 2012;21:1920-5.

11. Pasha S, Ilharreborde B, Baldwin K. Sagittal spinopelvic alignment after posterior spinal fusion in adolescent idiopathic scoliosis: a systematic review and meta-analysis. Spine (Phila Pa 1976) 2019;44:41-52.

12. Banno T, Togawa D, Arima H, et al. The cohort study for the determination of reference values for spinopelvic parameters (T1 pelvic angle and global tilt) in elderly volunteers. Eur Spine J 2016;25:3687-93.

13. Glassman SD, Bridwell K, Dimar JR, Horton W, Berven S, Schwab F. The impact of positive sagittal balance in adult spinal deformity. Spine (Phila Pa 1976) 2005;30:2024-9.

14. Lafage V, Schwab F, Patel A, Hawkinson N, Farcy JP. Pelvic tilt and truncal inclination: two key radiographic parameters in the setting of adults with spinal deformity. Spine (Phila Pa 1976) 2009;34:E599606.

15. Ogura Y, Shinozaki Y, Kobayashi Y, et al. Impact of sagittal spinopelvic alignment on clinical outcomes and health-related quality of life after decompression surgery without fusion for lumbar spinal stenosis. J Neurosurg Spine 2019:1-6.

16. Pimenta L, Tohmeh A, Jones D, et al. Rational decision making in a wide scenario of different minimally invasive lumbar interbody fusion approaches and devices. J Spine Surg 2018;4:142-55.

17. Kose KC, Bozduman O, Yenigul AE, Igrek S. Spinal osteotomies: indications, limits and pitfalls. EFORT 
Open Rev 2017;2:73-82.

18. Kanda Y. Investigation of the freely available easy-touse software 'EZR' for medical statistics. Bone Marrow Transplant 2013;48:452-8.

19. Briggs AM, Wrigley TV, Tully EA, Adams PE, Greig AM, Bennell KL. Radiographic measures of thoracic kyphosis in osteoporosis: Cobb and vertebral centroid angles. Skeletal Radiol 2007;36:761-7.

20. Ohrt-Nissen S, Cheung JP, Hallager DW, et al. Reproducibility of thoracic kyphosis measurements in patients with adolescent idiopathic scoliosis. Scoliosis Spinal Disord 2017;12:4.

21. Lafage V, Ames C, Schwab F, et al. Changes in thoracic kyphosis negatively impact sagittal alignment after lumbar pedicle subtraction osteotomy: a comprehensive radiographic analysis. Spine (Phila Pa 1976) 2012;37:E180-7.

22. Jackson RP, McManus AC. Radiographic analysis of sagittal plane alignment and balance in standing volunteers and patients with low back pain matched for age, sex, and size: a prospective controlled clinical study. Spine (Phila Pa 1976) 1994;19:1611-8.
23. Jalai CM, Cruz DL, Diebo BG, et al. Full-body analysis of age-adjusted alignment in adult spinal deformity patients and lower-limb compensation. Spine (Phila Pa 1976) 2017;42:653-61.

24. Lafage R, Schwab F, Challier V, et al. Defining spinopelvic alignment thresholds: should operative goals in adult spinal deformity surgery account for age? Spine (Phila Pa 1976) 2016;41:62-8.

25. Imrie M, Yaszay B, Bastrom TP, Wenger DR, Newton PO. Adolescent idiopathic scoliosis: should 100\% correction be the goal? J Pediatr Orthop 2011;31(1 Suppl):S9-13.

26. Nicholls FH, Bae J, Theologis AA, et al. Factors associated with the development of and revision for proximal junctional kyphosis in 440 consecutive adult spinal deformity patients. Spine (Phila Pa 1976) 2017;42:1693-8.

27. Terran J, Schwab F, Shaffrey CI, et al. The SRSSchwab adult spinal deformity classification: assessment and clinical correlations based on a prospective operative and nonoperative cohort. Neurosurgery 2013;73:559-68. 